NBER WORKING PAPER SERIES

\title{
IS THERE A DEMAND FOR REVERSE MORTGAGES IN CHINA? EVIDENCE FROM TWO ONLINE SURVEYS
}

\author{
Katja Hanewald \\ Hazel Bateman \\ Hanming Fang \\ Shang $\mathrm{Wu}$ \\ Working Paper 25491 \\ http://www.nber.org/papers/w25491 \\ NATIONAL BUREAU OF ECONOMIC RESEARCH \\ 1050 Massachusetts Avenue \\ Cambridge, MA 02138 \\ January 2019
}

The authors acknowledge the financial support from the ARC Centre of Excellence in Population Ageing Research (CEPAR) - CE17010005. We thank Olivia S. Mitchell, John Piggott, Thomas Post, Jennifer Alonso Garcia, and Ralph Stevens for valuable comments and suggestions. We also thank conference participants at the 22nd International Congress on Insurance: Mathematics and Economics in Sydney, at the International Conference on "Addressing Population Aging: Institutional and Public Policy Innovation" held at the ShanghaiTech University, and at the 26th Colloquium on Pensions and Retirement Research in Sydney. The views expressed herein are those of the authors and do not necessarily reflect the views of the National Bureau of Economic Research.

NBER working papers are circulated for discussion and comment purposes. They have not been peer-reviewed or been subject to the review by the NBER Board of Directors that accompanies official NBER publications.

(C) 2019 by Katja Hanewald, Hazel Bateman, Hanming Fang, and Shang Wu. All rights reserved. Short sections of text, not to exceed two paragraphs, may be quoted without explicit permission provided that full credit, including $(\odot)$ notice, is given to the source. 
Is There a Demand for Reverse Mortgages in China? Evidence from Two Online Surveys Katja Hanewald, Hazel Bateman, Hanming Fang, and Shang Wu

NBER Working Paper No. 25491

January 2019

JEL No. D14,G11,G21,G22

\begin{abstract}
Reverse mortgages provide an alternative source of retirement funding by allowing older homeowners to borrow against their home. However, a recent pilot program of reserve mortgage products in several large Chinese cities saw almost no take up. To ascertain the demand for reverse mortgages in China, we conduct and analyze two online surveys that focus respectively on homeowners aged 45-65 as potential purchasers, and on adult children in the 20-49 age group representing children of potential purchasers. We address the reported shortcomings of the pilot reverse mortgage product by testing an improved product design presented in a clear and comprehensive format. In stark contrast, we find that $89 \%$ of older Chinese homeowners would be interested in this new reverse mortgage product, and $84 \%$ of adult children would recommend such a product to their parents. Participants in both surveys reported that they would use the reverse mortgage payments to fund a more comfortable retirement and to pay for better medical treatments and aged care services. Respondents' interest in reverse mortgages was associated with their familiarity and understanding of the product, and its perceived potential to address liquidity constraints in retirement. Health status, aged care preferences and proxies for intergenerational links were also important. Our results are contrary to the common perception of intergenerational expectations of wealth transfer in China, and provide new evidence in support of the potential development of China's reverse mortgage market.
\end{abstract}

Katja Hanewald

ARC Centre of Excellence in Population Ageing Research UNSW Sydney

Sydney, NSW, 2052, Australia

k.hanewald@unsw.edu.au

Hazel Bateman

School of Risk and Actuarial Studies

ARC Centre of Excellence in Population

Ageing Research (CEPAR)

UNSW Sydney, 2052 Australia

H.Bateman@unsw.edu.au
Hanming Fang

Deparrtment of Economics

Ronald O. Perelman Center

for Political Science and Economics

133 South 36 th Street

Suite 150

Philadelphia, PA 19104

and NBER

hanming.fang@econ.upenn.edu

Shang Wu

First State Super and CEPAR, University of New South Wales

shang_wu@firststatesuper.com.au 


\section{Introduction}

China's large population is aging rapidly. The median age is projected to climb from 37 years in 2015 to 48 years in 2050, and is expected to exceed the median age of high-income countries from 2035 onwards (United Nations, 2017). In 2015, 215 million people aged 60 and above (or 24\% of the world's older population) lived in China. This number is expected to increase to 479 million by 2050 and will then comprise $23 \%$ of the world's elderly population (United Nations, 2017). China's elderly will require significant and increasing resources to finance their retirement income, health care and aged care costs - needs that will place an enormous pressure on the financial viability of the social security systems in China (Fang and Feng, 2018).

To explore new ways to fund retirement, the Chinese government initiated a pilot program to facilitate the take-up of reverse mortgage products in urban China. Reverse mortgages allow older homeowners to borrow against the equity in their home. Payment options can include a lump sum, a regular income stream, a line of credit or a combination of these options. There are no repayments of interest or principal while the borrower lives in his/her home. Instead, the property is sold when the borrower dies or vacates the home, and the sale proceeds are used to repay the loan including interest and fees (e.g., Mitchell and Piggott, 2004; Nakajima and Telyukova, 2017). Reverse mortgage products are available in the U.S., Australia, Canada, some European countries, and New Zealand, and are emerging in a number of East Asian economies such as Japan, Korea, Hong Kong, Singapore and Taiwan (Merton and Lai, 2016; Phang, 2018).

The Chinese reverse mortgage pilot program was introduced in mid-2014 by Happy Life Insurance Company in four cities (Beijing, Shanghai, Guangzhou and Wuhan) and was extended to other major cities in 2016 and then nationwide in August 2018. ${ }^{1}$ The pilot program has not been successful: Only one provider is offering reverse mortgage products and the demand is low. By the end of June 2018, only 139 contracts (with 98 households) were underwritten. News reports list several factors explaining this low demand, including children disapproving of their parents reverse mortgaging their homes, product complexity, legal and regulatory concerns, and high interest rates charged by the provider (Merton and Lai, 2016; Asia Insurance Review, 2017).

In this paper, we use survey methods to investigate the stated demand (or lack thereof) for reverse mortgage products in China. In order to explore the role of the perceived intergenerational expectations of wealth transfer (Merton and Lai, 2016), we test whether the acceptance of reverse mortgages differs be-

\footnotetext{
${ }^{1}$ See Notice No. 43 [2018] of the China Banking and Insurance Regulatory Commission on Expanding the Scope of the Elderly Housing Reverse Mortgage Endowment Insurance, which was released on 8 August 2018 (http://bxjg.circ.gov . cn/ web/site0/tab5168/info4115825.htm).
} 
tween older homeowners and their adult children. We designed a reverse mortgage product with the aim of addressing some of the key problems identified in the current Chinese market, and the recent literature on reverse mortgages in general (Davidoff et al., 2017; Dillingh et al., 2017; Fornero et al., 2016; Jefferson et al., 2017) and took special care to provide a clear product description. In two large online surveys, we asked older homeowners whether they would be interested in the reverse mortgage product we present, and we also asked the working-age adult children of older homeowners whether they would recommend the product to their parents. Both groups were then asked to identify how they would like to use the reverse mortgage payments. Our total sample comprised 2,200 participants living in 64 large cities in China.

Reverse mortgages can serve multiple purposes. Retirees can use the additional liquid wealth, for example, to afford a more comfortable lifestyle, to cover medical costs and to pay for formal aged care services. Reverse mortgages also allow families to better time their bequests and reduce the uncertainty around bequest timing (Merton, 2008; Dillingh et al., 2017). We test how the interest in reverse mortgages in China varies according to the way in which a reverse mortgage is described. In particular, we focus on four different framings of how the reverse mortgage payment is to be used - to increase own consumption, to finance better medical treatments and/or aged care services, to support children or grandchildren, or to have more financial flexibility in retirement, together with a group with no payment use framing - and randomly assign participants into these treatment groups.

We find that the product design and presentation format we developed using focus group testing was successful: Both older homeowner and adult children participants rated their product understanding as high and scored well in a product knowledge quiz. Interest in the reverse mortgage was strong for both groups. $89 \%$ of the older homeowners stated interest in the reverse mortgage product and $84 \%$ of the adult children said they would recommend such a product to their parents. This is in stark contrast to the common perception that strong expectations of intergenerational wealth transfer act as a barrier to the development of reverse mortgage market in China, but consistent with an emerging literature (Zhong and $\mathrm{Li}$, 2017). For both samples, demand was similarly high under all product use framing treatments, which we attribute to the overall high product understanding. Participants stated that they would use (or recommend the use of) the reverse mortgage payments for a range of purposes, including to live more comfortably in retirement, to pay for better medical treatments or aged care services, to support children or grandchildren, and to have greater financial flexibility in retirement.

Our study contributes to the growing literature on the demand for reverse mortgages. Theoretical studies document welfare gains of reverse mortgages in life-cycle models (e.g., Davidoff, 2009; Cocco and Lopes, 2014; Hanewald et al., 2016), while recent studies attempt to explain why demand is low in many markets 
(Nakajima and Telyukova, 2017; Andreu et al., 2018). Our paper is most closely related to several empirical papers that use survey methods to investigate reverse mortgage demand. These studies have focused on the (low) demand for reverse mortgage products in high-income countries such as Australia (Jefferson et al., 2017), Italy (Fornero et al., 2016), the Netherlands (Dillingh et al., 2017) and the U.S. (Davidoff et al., 2017; Moulton et al., 2017). Research on reverse mortgage demand in middle- and low-income countries is less developed. In conducting our study in China we make an important contribution to the potential for a reverse mortgage market in countries where cultural expectations may be perceived to be a barrier to its development.

We provide important new evidence on the potential demand for reverse mortgages in urban China. China has a large aging population, but an underdeveloped market for retirement income products. The Chinese government has identified reverse mortgages as a tool to provide additional retirement income without the need to increase public funding, but the current reverse mortgage program fails to attract interest. We develop a reverse mortgage product with characteristics and an accompanying presentation format that facilitates both product understanding and product acceptance. Significantly, in contrast to perceived cultural norms, we find strong interest by both the older homeowner and adult children participants. Product familiarity and understanding, as well as the likelihood of liquidity constraints in retirement, were associated with a higher interest in the reverse mortgage product. Health status, aged care preferences and proxies for intergenerational links also impacted the demand. Overall, our results suggest that there is a potential market for reverse mortgages among educated urban Chinese. The presentation format we developed can be used as a basis for the relevant distribution networks to develop this potentially large market.

The remainder of the paper is organized as follows. In Section 2, we review the basic facts about housing wealth and property rights in China, and describe the current reverse mortgage pilot program. In Section

3, we describe our two surveys that respectively elicit interest in reverse mortgage products by older homeowners and adult children. In Section 4, we present descriptive statistics from our survey data. In Section 5, we discuss our regression results. In Section 6, we conclude with a discussion of the implications of our results for the design and marketing of reverse mortgages in the Chinese market.

\section{Background}

\subsection{Housing wealth and property rights}

Homeownership rates are high in China and housing is the largest component of household wealth. In the 2011 national baseline survey of the China Health and Retirement Longitudinal Study (CHARLS), 88\% 
of urban residents and 92\% of rural residents aged 45+ lived in households owning at least one property (Park and Shen, 2015). Gan et al. (2014) found similar home ownership rates (88\% and 95\% respectively for urban and rural households) using the 2012 China Household Finance Survey. Housing equity comprised $85 \%$ of total wealth for urban residents and 74\% for rural residents (Park and Shen, 2015). Similarly, Xie and Jin (2015) found, using the 2012 Chinese Family Panel Survey, that housing wealth accounted for 79\% and $61 \%$ of the household wealth for urban and rural residents respectively. Both the homeownership rates and the fractions of housing wealth in household wealth in China are significantly higher than those in the United States.

Despite the fact that China only started privatizing its housing sector since the 1990s, Chinese homeowners have enjoyed rapid house price growth. For the period 2003-2013, Fang et al. (2016) compute the average annual real growth rates of $13.1 \%$ for Tier I cities (Beijing, Shanghai, Guangzhou, and Shenzhen), $10.5 \%$ in Tier II cities and 7.9\% in Tier III cities. A reverse mortgage product would allow older homeowners to access their housing wealth without having to move, while increasing the financial resources to fund retirement without requiring additional savings or public financing (Merton and Lai, 2016).

Property rights in China are sometimes raised as a potential problem for the development of a reverse mortgage market. As it is well known, homeowners in China own their buildings, but not the land which belongs to the state or the collectives. Land users can obtain land use rights through a land grant contract. For residential properties, land use rights are granted for 70 years and can be transferred when the property is sold. However, we argue that the 70-year duration of the land use rights should not pose a risk for the development of reverse mortgages in China. First, the current property laws already allow for the extension upon the expiration of initial land use rights: Article 21 of the Urban Real Estate Administration Law regulates that homeowners can apply for an extension of their land use rights one year before their rights expire, while Article 149 of the Property Law even says that land use rights for residential construction land shall be renewed automatically. In addition, the current drafts of China's new Civil Code, which is expected to be finalized in 2020, clarify that land use rights shall be renewed automatically against the payment of renewals fees.

\subsection{Reverse mortgage pilot in China}

A reverse mortgage pilot program was introduced in 2014 in four cities (Beijing, Shanghai, Guangzhou and Wuhan) and has since been extended to a national program. So far two companies have received approval from the China Insurance Regulatory Commission to sell reverse mortgages. Happy Life Insurance have offered a product called "Housing provides guarantee reverse mortgage endowment insurance for the elderly" since March 2015 and is actively selling this product in eight cities in China (Beijing, Shanghai, 
Guangzhou, Wuhan, Hangzhou, Dalian, Nanjing, Suzhou). The People's Insurance Company of China (PICC) also received approval for a product called "Living in peace and happiness reverse mortgage endowment insurance for the elderly" in October 2016 but has not started selling the product.

An English translation of the Happy Life Insurance product description can be found in Appendix A. The product is complex (compared with the standard reverse mortgage product offered in other markets) and the associated product description lacks clarity. In brief, the "Happy Life" reverse mortgage product provides fixed monthly payments for life which are partly structured as a deferred annuity. For a fixed period (e.g. 26 years for a 60-year-old, 18 years for a 70-year-old), the monthly payments increase the loan balance and an additional annual "deferred annuity premium" is added to the loan balance. After the fixed period, the loan balance only accrues interest while the purchaser still receives the same monthly payments. The amount of the monthly payment depends on the property value, the age and sex of the purchaser. For couples, the monthly payments are calculated based on the percentage ownership of the property. Purchasers can choose a death benefit at extra costs while several types of fees are subtracted from the regular income payments.

As well as its complexity, the Happy Life Insurance reverse mortgage product piloted in China is inflexible. Under current product design, the only payment type offered is a fixed income stream, which does not allow purchasers to cover large unexpected expenditures in retirement. Similar products offered in other markets typically offer a choice of regular income stream, a lump sum, a line of credit, or a combination thereof. Furthermore, purchasers of the Happy Life Insurance reverse mortgage product are unable to choose the level of debt they will incur.

As we mentioned in the introduction, the demand for Happy Life's reserve mortgage product is minuscule: by the end of June 2018, only 139 contracts (with 98 households) were underwritten. Given the aforementioned issues of the Happy Life's reverse mortgage contract design, it is not clear whether the lack of the demand for reserve mortgage product is due to its contract design, or is it because of other more fundamental issues that may lead to Chinese consumers' aversion to reverse mortgages. To address these issues, we test a more general, flexible product design, taking particular care to ensure the clarity of the product description, as described in the following section.

\section{Survey design}

We designed two surveys to ascertain the potential demand for reverse mortgages in urban China. Survey 1 targeted urban homeowners aged 45-69 years as potential borrowers (the older homeowner sample), while Survey 2 focused on adult children (ages 20-49) of urban homeowners (the adult children sample). Both groups saw the product description of a hypothetical reverse mortgage and were asked to state 
their interest in the product. Using these parallel surveys, we tested whether the acceptance of reverse mortgages differed between older homeowners and adult children. The design of the two surveys was similar: We used similar screening questions, similar questions to elicit reverse mortgage demand and collected similar covariates. However, each survey included additional questions tailored to the specific sample, which were partly designed to provide proxies for intergenerational expectations. Screenshots of the English version of the surveys are provided in Appendix B and C. ${ }^{2}$

The two surveys were fielded between 18-26 October 2017 by the online survey firm dataSpring to two samples of 1,100 participants each. dataSpring recruited the participants by email from their panel of over 1 million Chinese. Participants were required to complete a participant information and consent form prior to commencing the survey and were paid around USD 1.70 for a completed survey. The median completion time was 16 minutes for Survey 1 (fielded to the older homeowner sample) and 17 minutes for Survey 2 (fielded to the adult children sample).

\subsection{Focus group testing}

We developed the first drafts of the two surveys based on existing international studies on reverse mortgage demand and informed by media reports about the reverse mortgage pilot program in China. However, given the unfamiliarity of most people with reverse mortgages and the perceived complexity of such products, we used focus groups to pre-test the survey design, including the design and description of the reverse mortgage product we proposed. The focus group discussions were conducted by the market research company Horizon Dataway in Beijing, China, on 29 July 2017. Two focus groups with six participants each were asked to discuss a first draft of key survey questions for two hours. Participants were recruited in line with the screening criteria for our main survey: one group comprised urban homeowners aged 50-69 with a second group of adult children aged 25-49 with parents owning at least one property. The discussions in both groups were led by a moderator from Horizon Dataway using a script we provided.

The focus group discussions, which are video recorded, helped us to substantially improve the questionnaires for both surveys. Participants in both focus groups asked very detailed questions about the features of our proposed 'hypothetical' reverse mortgage product, which led us to develop a product description that is more detailed than the brief product descriptions used in previous empirical studies (Dillingh et al., 2017; Fornero et al., 2016). For example, focus group participants asked how the property value would

\footnotetext{
${ }^{2}$ The surveys can be accessed here: Survey 1 (Ages 45-69): English: https://d8aspring. post-survey . com/preview/index . php?key=HGpme4zE\&lang_c=en, Chinese: https://d8aspring.post-survey.com/preview/index $\cdot$ php?key=YVvmVRMK\&lang_c= en; Survey 2 (Ages 20-49): English: https://d8aspring.post-survey.com/preview/index.php?key=hjHygupq\&lang_c=en, Chinese: https://d8aspring.post-survey.com/preview/index.php?key=I8qQImaU\&lang_c=en.
} 
be determined at the beginning and the end of the contract, what types of company would provide the reverse mortgage, whether the government would provide a guarantee in the event of provider default, how product payments would be affected by tax, and whether the property could be rented out after signing the contract. The participants also reported that a numerical example was essential to understand the reverse mortgage product. We therefore included a numerical example in the final version of each survey. The focus group testing also helped us to refine the Chinese translations of the survey questions.

\subsection{Survey 1 (Participants aged 45-69)}

Survey 1 targeted urban homeowners aged 45-69 years who could be potential reverse mortgage borrowers. We set quotas for five-year age groups to ensure that the age distribution of the sample matched the age distribution of the "Population number in city areas" in the 2010 Chinese census shifted forward by five years. We included participants from 64 cities and required 50\% to reside in Tier I cities (Beijing, Shanghai, Guangzhou or Shenzhen) and $50 \%$ to live in Tier II or Tier III cities. ${ }^{3}$ We included participants only if they had lived in the city for more than one year. To identify homeowners, we asked participants whether they or their spouse own a property (excluding houses and properties without an owner certificate).

\subsubsection{Product description and understanding}

The survey began with several "warm up" questions about participants' household income, housing wealth and mortgage debt. We then showed participants the description of a hypothetical reverse mortgage product. We developed this product description based on reports in the Chinese media about the reverse mortgage pilot, the related academic literature on reverse mortgage demand internationally and using the insights gained in the focus groups. The product description is far more detailed than the brief (one-paragraph) product descriptions used in related empirical studies on reverse mortgage demand in the Netherlands and Italy (Dillingh et al., 2017; Fornero et al., 2016). In drafting the product description, we directly addressed common concerns about reverse mortgages as described in Section 3.1. We called the product 'product $\mathrm{ABC}$ ' to address any (positive or negative) connection with existing similarly named products.

The main differences in the product design between the reverse mortgage offered in China by Happy Life Insurance and the hypothetical reverse mortgage product ABC are as follows. (1) The Happy Life Insurance product only offers one payment type, a fixed monthly income stream. Product ABC allows purchasers to choose how they will be paid. Purchasers can choose between a lump sum, lifetime fixed

\footnotetext{
${ }^{3}$ There is no official tier classification in China. We classify Beijing, Guangzhou, Shanghai and Shenzhen as Tier I cities. Tier II cities include, for example, Tianjin, Chongqing, Wuhan, and Chengdu.
} 
regular payments or flexible payments depending on their needs. This feature allows individuals to finance larger expenditures in retirement such as medical costs, gifts to children or grandchildren, or home renovations. (2) The value of the monthly payments from the Happy Life Insurance product depends on the value of the property, the age and gender of the purchaser. Purchasers cannot choose the level of debt they will incur. Our hypothetical product ABC allows purchasers to choose the level of payments (within limits depending on the property value, the purchaser's age and gender), which determines the level of debt. (3) The payments of the Happy Life Insurance product are partly structured as a deferred annuity as described in Section 2.2, which makes the product complex and hard to understand. Product ABC is simpler: each payment the purchaser receives becomes a debt which accumulates interest. (4) The Happy Life Insurance product features several different types of fees, including a set-up fee, fees for lapses and surrender, fees for selling the property after the purchaser passed away, and an annual administration fees of CNY 1,000 (USD 148). Product ABC does not have additional fees.

The following is the English translation of the description of product ABC presented to survey participants. We used bold font to emphasize key product features.

We are now going to describe a new financial product to you. Please read the description carefully.

Product $A B C$ allows retired homeowners to use their home as a collateral to receive cash payments, while allowing them to still own and live in the property. Product $A B C$ is offered by a large state-owned Chinese bank, with a guarantee from the government for the payments.

This product has the following characteristics:

At the beginning of the contract:

- You can choose how much and how you will be paid. You can choose between a lump sum, lifetime fixed regular payments or flexible payments depending on your needs.

- The maximum value of these payments depends on the value of your property at the beginning of the contract, your age, the age of your spouse and other factors.

- The value of the property is assessed by an independent, authorized appraiser.

While you and your spouse are alive:

- You receive the payments you have chosen in cash or as bank transfers.

- You do not have to repay the payments while you and your spouse are alive.

- Instead the payments become a debt, which accumulates interest. The interest rate is fixed at the beginning of the contract and will not change over the period of the contract. The interest rate is 1-2 percentage points higher than standard mortgage rates.

- You retain full ownership of the property and whatever value it may have in the future. 
- You and your spouse have a guaranteed right to live in your property while you are alive.

- You and your spouse can rent out the property and keep the rental income.

- If for any reason the property is lost in a natural disaster, the bank will settle the contract with an insurance company and compensate you in a fair way.

After both you and your spouse have passed away:

- The product provider will sell your property at the highest possible market price.

- The sale proceeds will be used to repay the debt.

- If the sale proceeds are higher than the debt, your heirs will receive any amount remaining after the debt has been repaid.

- If the sale proceeds are insufficient to cover the debt, your heirs will not be liable to pay any additional money. The product provider is responsible for the difference and bears the risk.

The following options may also be included in product $A B C$ :

- The purchaser and his/her spouse can terminate the contract early by prepaying the debt.

- The purchaser's heirs can repay the debt and keep the property after the purchaser and his/her spouse have passed away.

Please assume that there are no taxes on any of the above payments.

On the same screen as the product description we asked participants whether they had ever heard of such a product. To ensure participants read the description of product ABC carefully, a screen timer precluded advancement to the next screen for at least one minute.

Informed by the feedback from the focus groups, we then showed participants the following numerical example of product $\mathrm{ABC}$ with the aim of increasing their understanding.

The following example illustrates how product $A B C$ works.

Mr. and Mrs. Zheng are 67 and 65 years old in 2017. They live in their own apartment in Beijing which is worth 5 million Yuan. They decide to use product $A B C$ to increase their retirement income.

At the beginning of the contract:

- They choose a type of payment (a lump sum, lifetime fixed regular payments or flexible payments as needed).

- The product provider offers them payments up to a maximum of 2.5 million Yuan in the 2017 value of $R M B$, which is equivalent to 50\% of their house value in 2017.

- They choose the amounts of the payments. They choose to receive in total 2 million Yuan, which is 
equivalent to $40 \%$ of their house value in 2017.

- They choose to include an option for their daughter to repay the debt and keep the property after they have passed away.

While at least one of the partners is alive:

- Mr. and Mrs. Zheng receive the payments from product ABC in cash or as bank transfers.

- They do not have to repay the payments while any one of them is alive. Instead these payments become a debt. As Mr. and Mrs. Zheng receive these payments, the amount of debt increases and accumulates interest at a fixed interest rate of $6 \%$ p.a.

- The couple fully owns their apartment, including all growth in the value of the apartment, if there is any.

- Each spouse has a guaranteed right to live in their apartment as long as he/she is alive.

Mr. Zheng passes away at age 77, but Mrs. Zheng lives until age 82. When Mrs. Zheng passes away in 2034 , the outstanding debt amount accumulated from the monthly payments is 5.5 million Yuan. Then, three scenarios are possible in 2034:

- Scenario A: The product provider sells the apartment at a price of 11.5 million Yuan. The money from the apartment sale is used to repay the debt. The daughter of Mr. and Mrs. Zheng inherits the remaining 6 million Yuan.

- Scenario B: The product provider sells the apartment at a price of only 5 million Yuan. The whole amount goes to the product provider. The daughter of Mr. and Mrs. Zheng inherits nothing but she is also not liable to for the difference of 0.5 million Yuan. The difference is a loss to the product provider.

- Scenario C: The daughter of Mr. and Mrs. Zheng decides to repay the debt of 5.5 million Yuan herself and keep the apartment.

Following the numerical example, participants were asked to rate their (subjective) understanding of product ABC and could choose between "Completely clear", "Mostly clear", "Generally clear", "Mostly confusing" and "Completely confusing". Later in the survey we tested participants' (objective) understanding of the reverse mortgage product using a quiz with eight true-false questions.

\subsubsection{Product framing}

We were interested to find out whether the stated demand for the reverse mortgage product is influenced by how the product is described, specifically in terms of how the payment is to be used. To provide a bit of context, Dillingh et al. (2017) found that Dutch homeowners aged 65 and above were more interested in a reverse mortgage when the product was described as a means of gifting money to children and grandchil- 
dren rather than in the alternative frame as a tool to supplement pension income. We expected that these two usages of reverse mortgage payments could also impact reverse mortgage demand in China where intergenerational transfers play an important role in household finance (see, e.g., Rosenzweig and Zhang, 2014). Chinese families often engage in an exchange where parents support their children's education, property purchases and child-rearing costs and receive (financial or in-kind) old age support in return. A reverse mortgage can ease the financial burden for both sides of this exchange, providing additional funding to support children and grandchildren, or to supplement retirement income.

Elderly Chinese also face potentially high health care costs and long-term care expenditures (e.g., World Bank, 2016, Ch. 6). This motivates an additional product frame describing reverse mortgages as a tool to pay for better medical treatments and/or better aged care services. Finally, we included a frame that described the reverse mortgage as a tool to have more flexibility in general to pay for any expenses in retirement.

To test whether reverse mortgage demand differs by the presentation frame of how the payment is to be used, we randomly assigned participants to five treatment groups and showed them different supplementary information about the potential use of the reverse mortgage payments. The first four groups were told "Retired homeowners can use the payments from ABC product, for example, but not limited to, to ...

- Live more comfortably in retirement, to afford (more) assistance with housekeeping, or to afford extras like a new car, travel or better furniture." (Frame 1)

- Pay for better medical treatments and/or better aged care services, including home care." (Frame 2)

- Support their children and/or grandchildren to pay for their education, pay for their wedding, help them buy a property or provide extra income for everyday expenses." (Frame 3)

- Have more flexibility to pay for any expenses in retirement." (Frame 4)

A fifth group were not provided with any additional information about the potential use of the reverse 
mortgage payments.

\subsubsection{Product demand and use of payments}

Following the product description and the numerical example, we asked participants the main survey question:

"Would you be interested in such a product if it was available? - (Yes/No)".

Interest in reverse mortgages represents a key stage in a consumer's financial decision making process. According to the stylized conceptual model presented in Bateman et al. (2014), consumers first need to be aware of a product and can then become interested. Interested consumers who face no constraints or barriers hindering their choice, can then decide whether to choose the product now, to delay the choice, or to never choose the product. The level of interest we elicit is therefore an indicator of the potential demand for reverse mortgages in the Chinese market.

We then asked those individuals who were interested in the reverse mortgage how they would use the payments from the product. To elicit the relative importance of the different options for using the payments, we asked participants to allocate 100 points across five options, which corresponded to main uses of reverse mortgages identified in the previous section: to live more comfortably in retirement, to afford (more) assistance with housekeeping, or to afford extras like a new car, travel or better furniture; pay for better medical treatments and/or better aged care services, including home care; support children and/or grandchildren to pay for their education, pay for their wedding, help them buy a property or provide extra income for everyday expenses; to have the flexibility to cover any expenses in retirement; and other uses.

Participants who reported that they would support their children and/or grandchildren were asked how they would like to do so. They could indicate whether they would like to pay for their children's or grandchildren's education, for their wedding, help them buy a property, provide extra income for every- 
day expenses or provide other support.

Participants who stated that they were not interested in product $A B C$ were asked why and could choose one or more reasons from a list of ten, drawn from those identified in previous research. These include bequest motives, debt aversion and distrust towards financial institutions (e.g., Andreu et al., 2018; Fornero et al., 2016; Jefferson et al., 2017).

\subsubsection{Collection of personal characteristics and other covariates}

We used the remainder of the survey to collect a large number of covariates including demographics, household income and wealth, financial literacy and numeracy measures, financial risk attitudes and personality traits, health and subjective life expectancy, information about children and grandchildren, and planned bequests, as well as expectations and preferences for aged care arrangements.

We used standard question formats for the covariates wherever possible to enable comparison with commonly used survey questions, such as from the China Health and Retirement Longitudinal Study (CHARLS) and similar surveys. These include the three financial literacy questions developed by Lusardi and Mitchell (2011a), as well as a set of questions to assess numeracy skills from Lipkus et al. (2001) and conscientiousness used, for example, in Agnew et al. (2016). Several questions were adopted from related survey research on reverse mortgages and life care annuities (Davidoff et al., 2017; Wu et al., 2018). These included three questions eliciting bequest motives and subjective evaluations of participants' retirement income and savings from Davidoff et al. (2017).

To identify whether participants paid attention to the survey, we included two instructional manipulation checks (IMCs) (Oppenheimer et al., 2009). ${ }^{4}$ The survey concluded with two exit questions which allowed participants to rate the clarity of the survey questions and to identify unclear questions.

\footnotetext{
${ }^{4}$ That is, we repeated two questions about household income at the end of the survey and compared answers with participants' first responses.
} 


\subsection{Survey 2 (Participants aged 20-49)}

To assess the strength of the cultural norms associated with the transfer of property between generations, we designed a second survey to investigate whether younger urban Chinese would recommend reverse mortgages to their parents. Survey 2 targeted urban residents aged 20-49 (adult children) whose parents own at least one property in an urban area. We used ten-year age quotas to ensure the age distribution of the sample matched the age distribution of the 'Population number in city areas' in the 2010 Chinese census shifted forward by five years. As for the elderly homeowner sample, we set quotas such that $50 \%$ of the participants were from Tier I cities and 50\% from the same Tier II or Tier III cities and had lived in the city for more than one year. The sample only included participants who have at least one live parent that lives in an urban area and owns a property (excluding houses and properties without an owner certificate).

Overall, Survey 2 (completed by the adult children sample) was very similar to Survey 1 (completed by the older homeowner sample) but differed with the inclusion of additional questions about the participants' parents. The survey began with questions about the household income, housing wealth and mortgage debt of the participant's parents. This was followed by the reverse mortgage tasks which were almost identical to the older homeowner version (Survey 1), as described in Section 3.2. The main difference was in the product description, where we referred to "a purchaser" instead of addressing participants directly using "you". We also altered "interest" in product $A B C$ " to "recommendation" to purchase product $\mathrm{ABC}$ and put the potential use of reverse mortgage payments in that context. That is, we asked participants:

- "Would you recommend this product to your parents if it was available? - (Yes/No)."

- "How would you advise your parents to use the payments from product ABC?"

- "Why would you not recommend product ABC to your parents?"

We then collected a large number of covariates on demographic, income and wealth and health for the par- 
ticipant and their parents, financial risk attitudes and personality traits, financial literacy and numeracy measures, information about children and siblings, and expectations and preferences for parental aged care arrangements. Two exit questions allowed participants to rate the clarity of the survey questions and to identify unclear questions.

\section{Descriptive statistics}

\subsection{Sample demographics}

Table 1 reports the summary statistics of the key demographic variables for participants who completed each survey and compares these with nationally representative data from the 2015 wave of the China Health and Retirement Longitudinal Study (CHARLS). The two samples differ because of the different age groups targeted. The mean age of the older homeowners who completed Survey 1 was 52.6 years compared to 34.0 years for the adult children who completed Survey 2. The "older" sample (Survey 1) were more likely to be married (97\% vs. $76 \%$ for the "adult children" sample) and have more children (1.1 children vs. 0.8 in Survey 2). The older homeowner participants in Survey 1 also own more properties (1.5 vs. 1.1 in Survey 2), and had higher household savings than the adult children participants in Survey 2. However, levels of household debt were similar. Both samples were highly educated: $78 \%$ of older homeowner participants in Survey 1 had a college degree, diploma, bachelor's or master's degree, and 93\% of the adult children participants in Survey 2.

The nationally representative data from CHARLS focuses on participants aged 45+, so we can only compare with the older homeowner sample. We report statistics for all CHARLS participants aged 45-69 with urban Hukou (the Chinese word for residence permit) who live in a household that owns at least one property. Income and wealth data is reported differently in CHARLS than in our survey, so we constructed measures to match the information collected in our surveys as closely as possible. The comparison confirms that our older homeowner sample is more educated and wealthier than the representative CHARLS sample. These differences are likely due to our online sampling method (which attracts more educated individuals), while CHARLS uses face-to-face interviews in the home, as well as the concentra- 
Table 1: Participant characteristics: Comparison with CHARLS 2015 data

\begin{tabular}{|c|c|c|c|}
\hline & Survey 1 (Ages 45-69) & Survey 2 (Ages 20-49) & CHARLS (Ages 45-69) \\
\hline & Older homeowners & Adult children & \\
\hline Age (mean) & 52.6 & 34.0 & 56.6 \\
\hline Male & $51.8 \%$ & $51.2 \%$ & $52.1 \%$ \\
\hline Married & $97.3 \%$ & $76.0 \%$ & $93.2 \%$ \\
\hline Number of children (mean) & 1.1 & 0.8 & 2.1 \\
\hline Number of properties & 1.5 & 1.2 & 1.1 \\
\hline Personal income (median) & n.a. & $¥ 80,000$ - $¥ 89,999$ & {$[¥ 18,150]$} \\
\hline $\mathrm{HH}$ income (median) & $¥ 100,000$ - $¥ 109,999$ & n.a. & {$[¥ 52,154]$} \\
\hline HH savings (median) & $¥ 250,000$ - $¥ 499,999$ & $¥ 100,000-¥ 249,999$ & {$[¥ 8,750]$} \\
\hline HH debt excl. mortgages (median) & $¥ 2,000-¥ 9,999$ & $¥ 2,000-¥ 9,999$ & {$[¥ 0]$} \\
\hline \multicolumn{4}{|l|}{ Highest education attained } \\
\hline No schooling & $0.1 \%$ & $0.0 \%$ & $9.4 \%$ \\
\hline Primary school & $1.0 \%$ & $0.1 \%$ & $30.4 \%$ \\
\hline Junior middle school & $3.6 \%$ & $0.5 \%$ & $29.0 \%$ \\
\hline Senior middle school & $17.2 \%$ & $6.4 \%$ & $16.3 \%$ \\
\hline College degree or Diploma & $30.4 \%$ & $19.5 \%$ & $11.9 \%$ \\
\hline Bachelor & $44.3 \%$ & $64.3 \%$ & $2.8 \%$ \\
\hline Master or above & $3.5 \%$ & $9.3 \%$ & $0.2 \%$ \\
\hline Current work status & $0.0 \%$ & 0 & 0 \\
\hline Employed full-time & $77.4 \%$ & $95.4 \%$ & $64.9 \%$ \\
\hline Employed part-time & $4.7 \%$ & $2.1 \%$ & $7.2 \%$ \\
\hline Retired & $17.0 \%$ & $0.2 \%$ & $26.7 \%$ \\
\hline Other & $0.9 \%$ & $2.4 \%$ & $1.2 \%$ \\
\hline Urban hukou & $99.4 \%$ & $95.6 \%$ & $100.0 \%$ \\
\hline $\mathrm{N}$ & 1,100 & 1,100 & 4,157 \\
\hline
\end{tabular}

Note: HH denotes household. CHARLS refers to the 2015 wave of the China Health and Retirement Longitudinal Study. [] indicates that variable definitions differ.

tion of survey participants in Tier I, II and III cities.

\subsection{Product understanding and survey clarity}

Reverse mortgage products are complex and difficult to understand for most potential purchasers (Davidoff et al., 2017). When developing the two surveys we paid close attention to the product design to address criticisms of the piloted Happy Life Insurance reverse mortgage product, as well as the product description to facilitate a better understanding of the product features. To gauge the understanding of our hypothetical reverse mortgage product (product $A B C$ ), we included both self-reported and objective measures of understanding in the surveys.

Most participants in both surveys had previously heard about reverse mortgage products. After reading 
the product description, $60 \%$ of the older homeowner participants in Survey 1 and $58 \%$ of the adult children participants in Survey 2 reported that they had heard of such a product before (see Table 2). Most likely, these participants heard about the current reverse mortgage pilot program described in Section 2.2.

Participants in both surveys reported high levels of product understanding following presentation of the product description and the numerical example. Choosing from five possible answers, $48 \%$ of older homeowner participants and $42 \%$ of adult children participants rated their understanding of product $A B C$ as completely clear. A further 48\% (54\%, respectively) of older homeowner (adult children, respectively) participants rated their understanding as mostly clear or generally clear. Only 5\% (4\%, respectively) of older homeowners (adult children, respectively) answered "mostly confusing" or "completely confusing".

We tested participants' knowledge of product $\mathrm{ABC}$ using a quiz with eight true-false questions. The responses show that the participants in both surveys understood the product description well. $23 \%$ of participants in the older homeowners sample answered all eight questions about specific product characteristics correctly, while $29 \%$ had only one or two incorrect answers. In the adult children survey, $21 \%$ of the participants answered all eight questions correctly, and 34\% had only one or two incorrect answers.

Participants found the surveys in general very clear, with close to $95 \%$ of participants in both samples rating the questions as completely or mostly clear.

\subsection{Demand for reverse mortgages and use of the payments}

The stated demand for the reverse mortgage product was high in both surveys. $89 \%$ of the older homeowner participants who completed Survey 1 said they were interested in the product, while $84 \%$ of the adult children participants from Survey 2 said they would recommend the product to their parents (see Figure 1).

Interest in the product was similarly high for all potential use frames. In both surveys, reverse mortgage 
Table 2: Product understanding and survey clarity

\begin{tabular}{|c|c|c|}
\hline & $\begin{array}{c}\text { Survey } 1 \text { (Ages 45-69) } \\
\text { Older homeowners }\end{array}$ & $\begin{array}{c}\text { Survey } 2 \text { (Ages 20-49) } \\
\text { Adult children }\end{array}$ \\
\hline \multicolumn{3}{|c|}{ Have you ever heard of such a product? } \\
\hline Yes & $60.1 \%$ & $57.5 \%$ \\
\hline No & $39.9 \%$ & $42.5 \%$ \\
\hline \multicolumn{3}{|c|}{ How do you rate your understanding of product $A B C$ ? } \\
\hline Completely clear & $47.6 \%$ & $41.5 \%$ \\
\hline Mostly clear & $33.5 \%$ & $35.6 \%$ \\
\hline Generally clear & $14.2 \%$ & $18.8 \%$ \\
\hline Mostly confusing & $3.7 \%$ & $3.5 \%$ \\
\hline Completely confusing & $0.9 \%$ & $0.6 \%$ \\
\hline \multicolumn{3}{|l|}{ Product knowledge quiz } \\
\hline All 8 answers correct & $23.4 \%$ & $20.5 \%$ \\
\hline 1 or 2 incorrect answers & $29.3 \%$ & $33.5 \%$ \\
\hline 3 or 4 incorrect answers & $36.3 \%$ & $38.3 \%$ \\
\hline More than 5 incorrect answers & $11.1 \%$ & $7.7 \%$ \\
\hline \multicolumn{3}{|c|}{ How clear do you think the questions in this survey were? } \\
\hline Completely clear & $66.6 \%$ & $63.1 \%$ \\
\hline Mostly clear & $28.3 \%$ & $32.0 \%$ \\
\hline Generally clear & $4.6 \%$ & $4.8 \%$ \\
\hline Mostly confusing & $0.5 \%$ & $0.1 \%$ \\
\hline Completely confusing & $0.0 \%$ & $0.0 \%$ \\
\hline $\mathrm{N}$ & 1,100 & 1,100 \\
\hline
\end{tabular}

demand was highest for Frame 4, which described the reverse mortgage as a means to have more financial flexibility in retirement. Under this frame, $90 \%$ of the older homeowner participants were interested in the reverse mortgage and $87 \%$ of adult children participants. Interest in reverse mortgages was lowest $(88 \%$ of older homeowner participants and $81 \%$ of adult children participants) for those in the control group who did not see additional information about the potential use of the product payments. However, these differences were not significant. ${ }^{5}$ We interpret this finding as an indication that the survey participants had such a clear understanding from the product description and numerical example that their interest in the reverse mortgage product $\mathrm{ABC}$ was not influenced by additional information on the potential use of the payments.

We asked the 977 older homeowner participants who were interested in reverse mortgage product ABC how they would use the payments from the product. Participants could allocate 100 points across five different options. Figure 2 shows that the older homeowner participants mostly wanted to use the payments to live more comfortably in retirement ( $29 \%$ allocated on average) and to pay for better medical

\footnotetext{
${ }^{5}$ We used two-sample $t$-tests to test whether reverse mortgage demand was significantly higher under Frames $1,2,3$ or 4 compared to the 'no framing' case. We found no significant differences in either sample.
} 
Figure 1: Interest in reverse mortgages, total and by framing treatment.

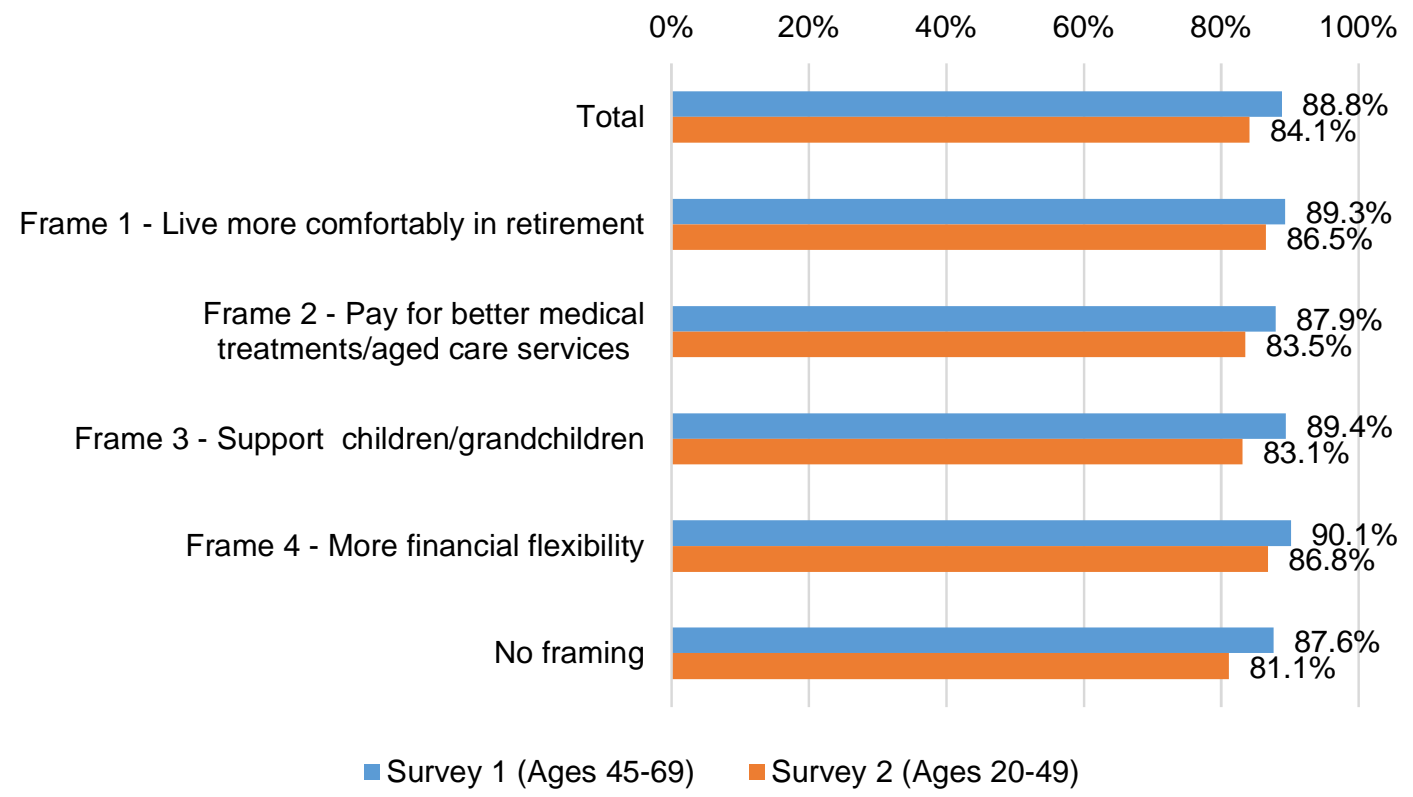

Note: Participants in Survey 1 (the older homeowners) reported whether they would be interested in the reverse mortgage if it was available. Participants in Survey 2 (adult children) reported whether they would you recommend the product to their parents if it was available.

treatments and/or better aged care services, including home care (28\%). Using the payments to support children and/or grandchildren was the third most popular (21\%), followed by more flexibility to pay for any expenses in retirement $(16 \%)$, and other reasons $(5 \%){ }^{6}$

We also asked the 925 adult children participants who said that they would recommend reverse mortgage product $\mathrm{ABC}$ to their parents how they would advise their parents to use the extra income. Interestingly, this group ranked the payment uses somewhat differently. They preferred that their parents use the payments from reverse mortgage product $\mathrm{ABC}$ to pay for better medical treatments/aged care services (31\% allocated on average), followed by "to live more comfortably in retirement" (28\%), to have more financial flexibility (19\%), to support children/grandchildren (18\%) and other uses (5\%) (see Figure 2). That is, the adult children (Survey 2) valued better medical treatments/aged care services more than the older homeowner participants (Survey 1), who preferred to use the payments to live more comfortably in retirement. The adult children put less emphasis on support for children/grandchildren than the older homeowner participants.

\footnotetext{
${ }^{6}$ We also analyzed the order in which participants ranked the different uses (see Section 5 and Appendix E).
} 
Figure 2: Use of reverse mortgage payments.

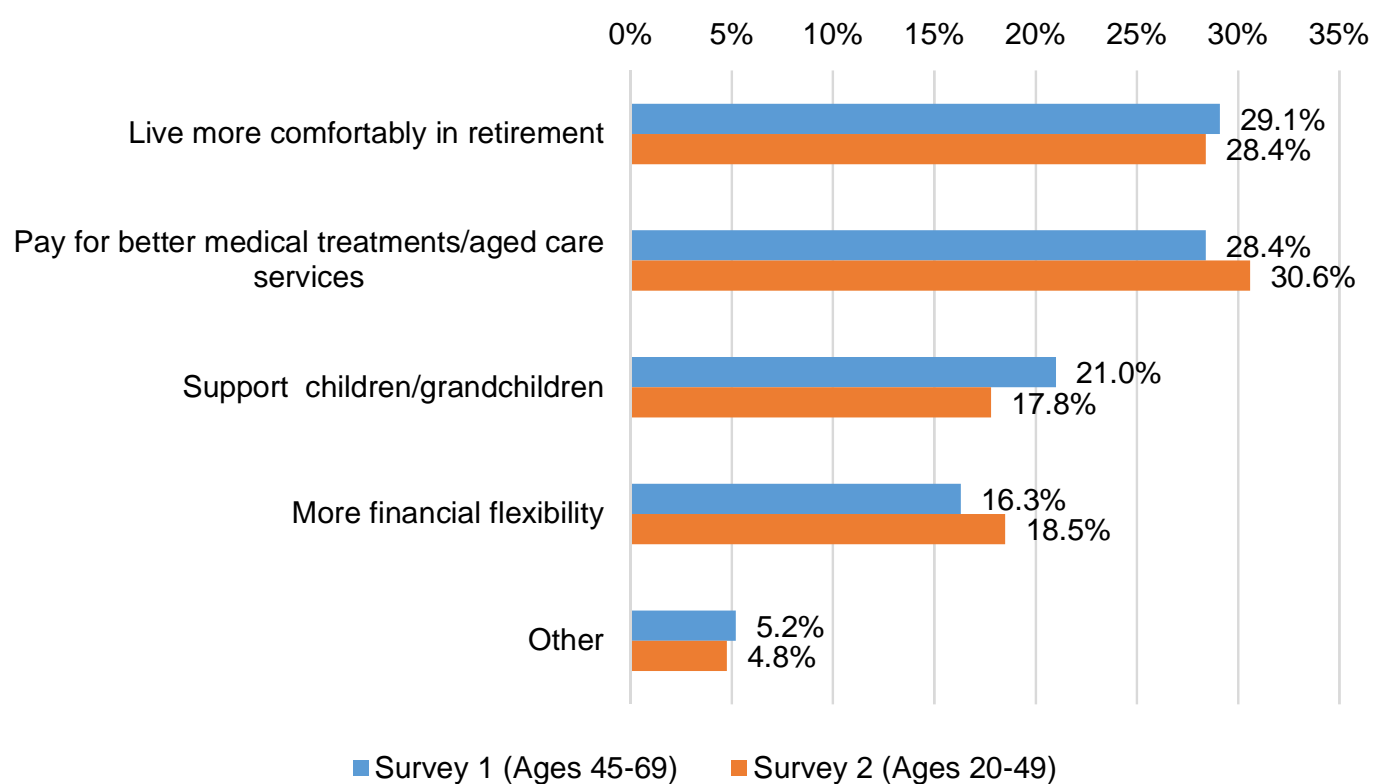

Note: Participants in Survey 1 reported how they would use the payments from the product. Participants in Survey 2 reported how they would advise their parents to use the payments.

Overall, these results show that the acceptance of home equity release was high in our two samples of educated urban Chinese. Older homeowners aged 45-69 were interested in the reverse mortgage product and adult children aged 20-49 would recommend the product to their parents. Both groups wanted to use the extra liquidity from the reverse mortgage for a range of purposes. The top two in both surveys were to live more comfortably in retirement and to pay for better medical treatments and/or aged care services. This level of interest in reverse mortgage products is substantially higher than what might be inferred from the minuscule take-up in the Happy Life Insurance pilot.

\subsection{Reasons for reverse mortgage rejection}

We asked the participants in both surveys who were not interested in the reverse mortgage (123 in Survey 1 and 175 in Survey 2 comprising 14\% of total participants) why they rejected reverse mortgage product ABC. Participants could choose all reasons that applied to them from a list of ten. As reported in Figure 3, the top three reasons for the older homeowner participants (Survey 1) to reject reverse mortgage product ABC were: "I want to leave my property to my children or grandchildren." (52\%), "I think the product is too complex." (40\%), and "I want to have as little debt as possible." (37\%). The adult children in Survey 
2 had different concerns. The top three reasons for them not to recommend product $A B C$ to their parents were: "They should have as little debt as possible." (44\%), "I do not think my parents would be interested in the product." (37\%), and "I think the product is too complex." (34\%).

Two differences stand out (see Figure 3). First, $52 \%$ of the older participants reported that they wanted to leave their property to their children or grandchildren while only $22 \%$ of the younger participants chose this a reason to reject recommendation of a reverse mortgage to their parents. Second, 37\% of the younger participants rejected the reverse mortgage because they did not think their parents would be interest in the product - an assumption which can be questioned given the high interest in reverse mortgages by the older homeowner participants (Survey 1). These findings suggest that older homeowners and their adult children may have inconsistent expectations regarding bequests and intergenerational property transfers. It is possible that reverse mortgage demand could be increased if families were encouraged to discuss intergenerational wealth transfers including bequest expectations and reverse mortgage decisions.

These results substantiate previous findings from developed countries that bequest motives, debt aversion, product complexity and distrust towards financial institutions are important factors leading individuals to reject reverse mortgages (see, e.g., Jefferson et al., 2017; Fornero et al., 2016; Davidoff et al., 2017).

\section{Regression results}

To better understand the factors influencing interest in reverse mortgage product $A B C$, and the use of the reverse mortgage product payments, we report the results from two sets of regressions. In the first set, we regress a dummy variable indicating whether the participant showed an 'interest' in reverse mortgages on presentation frame (for reverse mortgage payment use), product familiarity, product understanding, as well as covariates which have been identified as being associated with interest in reverse mortgage products - economic factors such as income, wealth, and indicators of income and savings adequacy; demographics; financial competence; personality traits; health status; and long term care expectations. In the second set, we regress the indicated alternative uses of reverse mortgage payments on similar 
Figure 3: Reasons for reverse mortgage rejection.

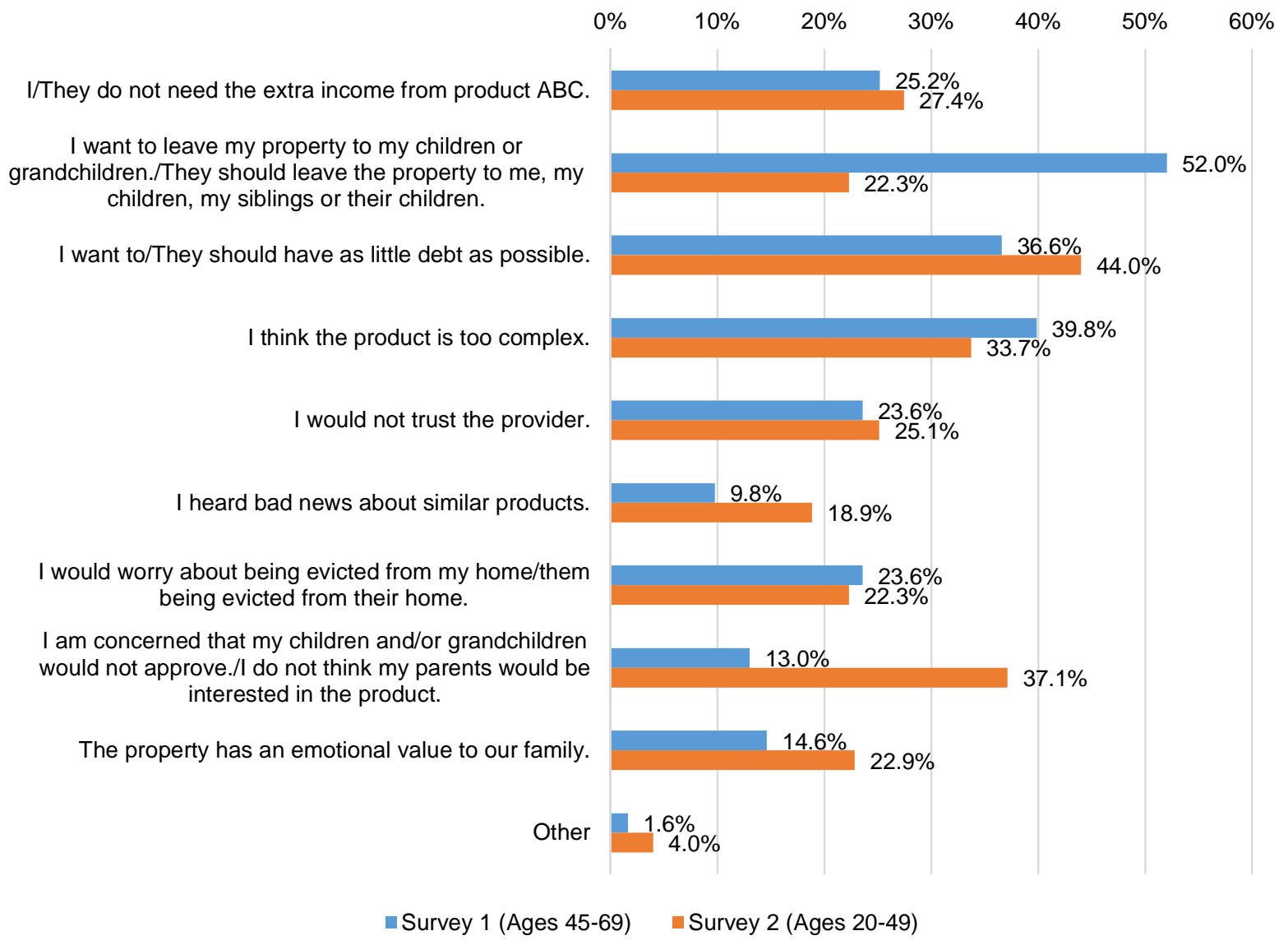

Note: Participants in Survey 1 reported why they are not interested in the reverse mortgage. Participants in Survey 2 reported why they would you not recommend the product to their parents. Participants could tick all answers that applied to them.

covariates. In both sets of estimations, we included indicators to measure 'attention' - specifically two Instructional Manipulation Checks (IMCs) and the time taken to complete the surveys.

The variable definitions are set out in in Appendix D. We coded most variables as binary variables. For ordinal and numeric variables, we defined binary variables where a level of one indicates that the participant's response is above the sample median. ${ }^{7}$

\footnotetext{
${ }^{7}$ See Agnew et al. (2016) for similar variable definitions. The variable 'Survey clarity' was excluded from the regression analysis because of insufficient variation in the data (see Table 2).
} 


\subsection{Factors explaining the interest in reverse mortgages}

Table 3 presents the results of probit regressions of the interest in the reverse mortgage product on product presentation frame, product familiarity, product understanding and key covariates drawn from economic theory and prior studies. We estimated four models: Models 1 and 3 are directly comparable as they include only variables included in both surveys. We focus our discussion on Models 2 and 4 which include additional covariates that differ between the two surveys, but are relevant for the respective samples.

Product knowledge and understanding: Participants who had previously heard of similar reverse mortgage products were significantly more interested in the reverse mortgage product ABC (in Survey 1) and were more likely to recommend the product to their parents (in Survey 2). Furthermore, participants with a higher self-rated understanding of the reverse mortgage product were also more interested in the product (significant at the 1\%-level for Survey 1; at the 10\%-level for Survey 2), although the level of objective product knowledge was not significant. These findings suggest that the extreme lack of interest in the Happy Life reverse mortgage product currently on offer should not be taken as indicative of reverse mortgage products per se.

Economic factors: We would expect that reverse mortgage products would be more appealing to participants with fewer economic resources to fund their retirement such as those with low incomes and limited savings. For the older homeowner sample (Model 2), we indeed find that participants with lower household savings and with lower ratings of the statements "I have/expect to have enough retirement income." were more interested in the reverse mortgage product. In the adult children sample, none of the economic factors were significant in Model 4.

Demographics: In terms of demographic characteristics we find that participants who were older, female, had a university degree, and were not retired were more likely to be interested in the reverse mortgage.

Financial competence: The conclusions of studies on the influence of financial competence on financial decisions is mixed. Several studies have found that the financially literate are more likely to plan for 
retirement (Lusardi and Mitchell, 2011b) and participate in the stock market (Van Rooij et al., 2011), while others suggest that the financially literate are less likely to purchase welfare enhancing life annuities (e.g., Agnew et al., 2008). This latter finding is consistent with related prior reverse mortgage studies which find that higher financial literacy is associated with lower interest in reverse mortgage products, and rationalize this result as the financially literate being otherwise better prepared for retirement (Fornero et al., 2016; Davidoff et al., 2017). In our study, the estimated effects for financial literacy differ between the two samples: Higher financial literacy scores were positively associated with interest in the reverse mortgage product by older homeowners (Survey 1) but negatively associated with the recommendation of the reverse mortgage product by adult children to their parents (Survey 2).

Personality traits: While one would expect that reverse mortgage products would be more appealing to the risk averse, for both older homeowners (Model 2) and adult children (Model 4), a higher self-reported willingness to take financial risks was associated with a higher interest in the reverse mortgage product ABC. However, patience (for older homeowners) and conscientiousness (adult children) were significantly and positively associated with interest in (recommendations of) the reverse mortgage product, as expected.

Overall, these regression results identify older homeowners with a higher interest in the reverse mortgage product $\mathrm{ABC}$ as having prior knowledge of reverse mortgages and an understanding of the specific product tested (consistent with Davidoff et al., 2017); being liquidity constrained in retirement (Davidoff et al., 2017; Dillingh et al., 2017); financially competent (relative to others in the sample of older homeowners); and a willingness to take risks (Fornero et al., 2016; Davidoff et al., 2017).

Similarly, key characteristics of adult children associated with them recommending reverse mortgages to their parents include knowledge and understanding and a willingness to take risks. However, higher levels of financial competence were associated with a lower likelihood to recommend, consistent with prior literature (Fornero et al., 2016; Davidoff et al., 2017).

We also collected additional covariates in each of the two surveys which allowed us to explore factors related to intergenerational expectations of care and wealth transfer which have been culturally more 
important in China than in developed western societies, that is on health status, aged care preferences and intergenerational transfers.

Health status and aged care preferences: As would be expected, higher interest in the reverse mortgage product was associated with expectations of remaining in the family home for long term. Specifically, older homeowners who rated their health better than one year ago were more likely to be interested in the product, while older homeowner participants who stated a preference to receive informal care or receive care in a nursing home were less interested in the product than those who preferred to receive care from a caregiver either living-in or visiting the home. On the other hand, neither health status or aged care preferences of parents were important to the adult children.

Intergenerational aspects: A key difference in our study as compared with prior research is that we collect data on proxies for intergenerational transfers. In this context we find that older homeowners with grandchildren were more likely to be interested, and that adult children with siblings and at least one child were more likely to recommend to their parents. In other words, the existence of grandchildren was associated with interest (recommendation) for both older homeowners and their adult children. Also important are bequest motives: our results indicate that older homeowners who would like to leave a bequest are less interested (consistent with economic theory and prior studies), while adult children who think their parents intend to leave a bequest would be more likely to recommend.

The results in Table 3 also show that the way in which the product was described - as a tool to increase own consumption (Frame 1), to finance better medical treatments and/or better aged care services (Frame 2), to support children and/or grandchildren (Frame 3), or to have more financial flexibility in retirement (Frame 4) - did not impact the interest in the reverse mortgage product: None of the four frames were significant in Models 1 and $4 .{ }^{8}$ It is possible that the comprehensive and clear product explanation offset the payment use framing.

\footnotetext{
${ }^{8}$ Nor for Models 1 and 3 with the exception of a significant and positive coefficient for Frame 4 in Model 3.
} 
Table 3: Explaining the interest in reverse mortgages.

\begin{tabular}{|c|c|c|c|c|}
\hline \multirow{3}{*}{$\begin{array}{l}\text { Survey } \\
\text { Dependent variable } \\
\text { Model }\end{array}$} & \multicolumn{2}{|c|}{$\begin{array}{c}\text { Survey } 1 \text { (Ages 45-69) } \\
\text { Older homeowners } \\
\text { Interest }\end{array}$} & \multicolumn{2}{|c|}{$\begin{array}{l}\text { Survey } 2 \text { (Ages 20-49) } \\
\text { Adult children } \\
\text { Recommend to parents }\end{array}$} \\
\hline & & & & \\
\hline & Model 1 & Model 2 & Model 3 & Model 4 \\
\hline \multicolumn{5}{|c|}{ Reverse mortgage knowledge and understanding } \\
\hline Product familiar & $0.374^{* *}$ & $0.340 *$ & $0.646^{* * *}$ & $0.696^{* * *}$ \\
\hline Product understanding & $0.422 * *$ & $0.432 * *$ & $0.225+$ & $0.224+$ \\
\hline Product quiz & 0.202 & 0.230 & 0.122 & 0.103 \\
\hline \multicolumn{5}{|l|}{ Reverse mortgage framing } \\
\hline Frame 1 & 0.153 & 0.189 & 0.222 & 0.220 \\
\hline Frame 2 & -0.024 & 0.036 & 0.121 & 0.098 \\
\hline Frame 3 & 0.136 & 0.131 & 0.101 & 0.074 \\
\hline Frame 4 & 0.157 & 0.213 & $0.285+$ & 0.242 \\
\hline \multicolumn{5}{|l|}{ Economic factors } \\
\hline Household income & -0.064 & -0.014 & & \\
\hline Personal income & & & 0.053 & 0.078 \\
\hline Household savings & $-0.291 *$ & $-0.265+$ & -0.096 & -0.054 \\
\hline Household debt & 0.132 & 0.053 & 0.189 & 0.202 \\
\hline No. properties & 0.000 & 0.011 & $0.234 *$ & $0.215+$ \\
\hline Property value & -0.050 & -0.090 & -0.063 & -0.025 \\
\hline Mortgage & 0.456 * & $0.487 *$ & 0.194 & 0.144 \\
\hline Private housing loan & -0.001 & -0.018 & -0.161 & -0.283 \\
\hline Stocks & 0.189 & $0.254+$ & -0.117 & -0.132 \\
\hline Sufficient income & & $-0.600 * * *$ & & \\
\hline Sufficient savings & & 0.196 & & \\
\hline \multicolumn{5}{|l|}{ Parents' economic factors } \\
\hline Parents household income & & & & -0.050 \\
\hline Parents no. properties & & & & -0.103 \\
\hline Parents property value & & & & 0.039 \\
\hline Parents mortgage & & & & -0.060 \\
\hline Parents private housing loan & & & & -0.345 \\
\hline Parents sufficient income & & & & -0.077 \\
\hline Parents sufficient savings & & & & -0.193 \\
\hline \multicolumn{5}{|l|}{ Financial competence } \\
\hline Financial literacy & $0.272+$ & $0.344 *$ & $-0.308 *$ & $-0.308 *$ \\
\hline Numeracy & $0.264 *$ & $0.270+$ & -0.099 & -0.040 \\
\hline \multicolumn{5}{|l|}{ Personality traits } \\
\hline Conscientiousness & 0.131 & 0.195 & $0.252+$ & $0.247+$ \\
\hline Patience & $0.275+$ & $0.303+$ & 0.193 & 0.184 \\
\hline WTR financial & $0.571^{* *}$ & $0.739 * * *$ & $0.778^{* * *}$ & $0.790 * * *$ \\
\hline \multicolumn{5}{|l|}{ Demographics } \\
\hline Age & $0.202 * *$ & $0.168 *$ & $-0.271^{* *}$ & $-0.213+$ \\
\hline Female & $0.315 *$ & $0.394^{* *}$ & -0.013 & -0.003 \\
\hline Married & -0.052 & -0.098 & -0.284 & -0.312 \\
\hline Tier 1 & 0.157 & 0.068 & -0.108 & -0.112 \\
\hline College or diploma & 0.143 & 0.111 & 0.122 & 0.112 \\
\hline University degree & $0.406^{* *}$ & $0.445^{* *}$ & 0.319 & $0.407+$ \\
\hline Private sector & 0.076 & 0.063 & $0.209+$ & 0.189 \\
\hline Retired & $-0.733^{* * *}$ & $-0.892 * * *$ & -1.056 & -0.726 \\
\hline \multicolumn{5}{|l|}{ Parents' demographics } \\
\hline Parents age & & & & -0.157 \\
\hline Parents college or diploma & & & & -0.083 \\
\hline Parents university & & & & -0.097 \\
\hline Parents private sector & & & & -0.051 \\
\hline Parents retired & & & & 0.120 \\
\hline \multicolumn{5}{|l|}{ Health and long-term care } \\
\hline Health & & 0.331 & & \\
\hline Health improved & & $0.472 * *$ & & \\
\hline ADL limitations & & 0.378 & & \\
\hline IADL limitations & & -0.283 & & \\
\hline Life expectancy & & -0.149 & & \\
\hline
\end{tabular}




\begin{tabular}{|c|c|c|c|c|}
\hline $\begin{array}{l}\text { Spouse health } \\
\text { Expect informal care } \\
\text { Expect nursing home } \\
\text { Prefer informal care } \\
\text { Prefer nursing home }\end{array}$ & & $\begin{array}{r}-0.015 \\
0.423+ \\
0.376+ \\
-0.484 * * \\
-0.395 *\end{array}$ & & \\
\hline $\begin{array}{l}\text { Parents' health and long-term care } \\
\text { Parents health } \\
\text { Parents ADL limitations } \\
\text { Parents IADL limitations } \\
\text { Expect informal care for parents } \\
\text { Expect nursing home for parents } \\
\text { Prefer informal care for parents } \\
\text { Prefer nursing home for parents }\end{array}$ & & & & $\begin{array}{r}0.241 \\
0.142 \\
-0.093 \\
0.198 \\
0.116 \\
-0.116 \\
-0.087\end{array}$ \\
\hline $\begin{array}{l}\text { Intergenerational aspects } \\
1 \text { child } \\
2+\text { children } \\
\text { Son } \\
\text { Child same HH } \\
\text { Grandchildren } \\
\text { Children personal income } \\
\text { Siblings } \\
\text { Parents same HH } \\
\text { Intended bequest } \\
\text { Parents intended bequest }\end{array}$ & $\begin{array}{l}0.447 \\
0.682 *\end{array}$ & $\begin{array}{l}0.342 \\
0.452 \\
0.111 \\
0.086 \\
0.426 \\
0.214\end{array}$ * & $\begin{array}{l}0.608^{* * *} \\
1.167^{* * *}\end{array}$ & $\begin{array}{l}0.358^{* *} \\
-0.123 \\
0.302 *\end{array}$ \\
\hline $\begin{array}{l}\text { Instructional Manipulation } \text { Check } \\
\text { Passed IMC } 1 \\
\text { Passed IMC } 2 \\
\text { Survey time }\end{array}$ & $\begin{array}{r}-0.100 \\
0.056 \\
-0.060\end{array}$ & $\begin{array}{r}-0.012 \\
0.005 \\
-0.035\end{array}$ & $\begin{array}{c}0.319+ \\
-0.385 * \\
0.285 *\end{array}$ & $\begin{array}{r}0.335 \text { + } \\
-0.433 \text { ** } \\
0.311 \text { ** }\end{array}$ \\
\hline Intercept & $-0.814+$ & -0.866 & 0.034 & 0.919 \\
\hline $\begin{array}{l}\mathrm{N} \\
\text { Likelihood Ratio test } \\
\text { Chi-Square } \\
\text { Pr > Chi-Square }\end{array}$ & $\begin{array}{l}159.1 \\
0.000\end{array}$ & $\begin{array}{l}1,100 \\
212.8 \\
0.000\end{array}$ & $\begin{array}{l}246.0 \\
0.000\end{array}$ & $\begin{array}{l}272.8 \\
0.000\end{array}$ \\
\hline
\end{tabular}

Note: This table gives the results of probit regressions of the interest in reverse mortgages on covariates. Variables are defined in Appendix D. ${ }^{+},{ }^{*}, * *$, and ${ }^{* * *}$ denote statistical significance at the $10 \%, 5 \%, 1 \%$, and $0.1 \%$ level, respectively.

\subsection{Factors explaining the use of reverse mortgage payments}

Participants who reported that they are interested in the reverse mortgage product ABC (in Survey 1) or would recommend the reverse mortgage product to their parents (in Survey 2) also reported how they would use the payments from the product. They were asked to allocate 100 points across five alternative options for the use of payments from the reverse mortgage product. We converted these percentages to ranks ranging from one (if the participant allocated most points to this use) to five (minimum points). Appendix E summarizes the rank data. The most popular uses of reverse mortgage payments for both the older homeowner and adult children samples were "to live more comfortably in retirement, to afford (more) assistance with housekeeping, or to afford extras like a new car, travel or better furniture" and to "Pay for better medical treatments and/or better aged care services, including home care." This finding 
is consistent with the average allocated percentages shown in Figure 2.

We model the ranked uses of the reverse mortgage payments on familiarity with and understanding of reverse mortgage products and other key covariates using ordered probit regressions. ${ }^{9}$ Table 4 reports the regression results for the older homeowner sample in Survey 1. Each column gives the results of one ordered probit model. As would be expected, we find that the alternative potential uses for the product payments are associated with different participant characteristics. The use of payments to live more comfortably in retirement was associated with good health - those who rated their health above the sample median, low household debt and not having a son, and was more likely for older participants with a tertiary degree. However, a preference to use the payments to fund medical and aged care expenses was associated with self-assessed health below the sample median (but a healthy spouse), having sufficient income and being risk averse, and living with economically productive children. On the other hand, a preference to use the payments to support children or grandchildren was associated with living with children and grandchildren and stronger intentions to leave a bequest, self-assessed health above the sample median and an expectation to receive informal care, and both less familiarity and low objective product knowledge of reverse mortgages. As would be expected, ranking financial flexibility as important was associated with having sufficient income, no children and weak bequest intentions, although also significant was not holding a tertiary degree and but poor objective (but good subjective) understanding of reverse mortgages.

Table 5 provides the corresponding regression results for the adult children sample in Survey 2. There are few significant covariates and the models for a more comfortable lifestyle and more financial flexibility do not fit the data well (the Likelihood Ratio test rejects both models). The adult children participants were more likely to advise their parents to use the reverse mortgage payments to pay for better medical care and/or better aged care if they rated their parents' health below the sample median and if they did not expect their parents to leave a bequest. At the same time, adult children were more likely to advise their parents to use the reverse mortgage payments to support children and/or grandchildren if they were male, had younger parents and expected their parents to leave a bequest.

\footnotetext{
${ }^{9}$ The dependent variable in these regressions has five response levels, corresponding to the five ranks.
} 
Table 4: Explaining the use of reverse mortgage payments - Survey 1 (Ages 45-69).

\begin{tabular}{|c|c|c|c|c|c|}
\hline Dependent variable & $\begin{array}{l}\text { Live more } \\
\text { comfortably }\end{array}$ & $\begin{array}{l}\text { Better medical/ } \\
\text { aged care }\end{array}$ & $\begin{array}{l}\text { Support grand/ } \\
\text { children }\end{array}$ & $\begin{array}{l}\text { Financial } \\
\text { flexibility }\end{array}$ & Other \\
\hline \multicolumn{6}{|c|}{ Reverse mortgage knowledge and understanding } \\
\hline Product familiar & 0.089 & -0.035 & $-0.160+$ & 0.110 & 0.103 \\
\hline Product understanding & -0.066 & -0.090 & -0.005 & $0.181 *$ & 0.074 \\
\hline Product quiz & 0.101 & 0.089 & $-0.266^{* *}$ & $-0.190 *$ & -0.065 \\
\hline \multicolumn{6}{|l|}{ Economic factors } \\
\hline Household income & -0.099 & 0.063 & 0.063 & -0.033 & $0.166+$ \\
\hline Household savings & 0.039 & -0.070 & -0.050 & -0.017 & 0.057 \\
\hline Household debt & $-0.175+$ & 0.004 & 0.026 & 0.084 & 0.130 \\
\hline No. properties & -0.002 & -0.020 & $-0.049 *$ & 0.016 & -0.010 \\
\hline Property value & 0.083 & 0.023 & 0.009 & -0.057 & $-0.348^{* * *}$ \\
\hline Mortgage & 0.144 & -0.008 & -0.032 & -0.041 & -0.011 \\
\hline Private housing loan & 0.177 & 0.071 & 0.117 & -0.131 & 0.189 \\
\hline Stocks & 0.065 & 0.008 & -0.022 & 0.013 & $-0.228 *$ \\
\hline Sufficient income & 0.121 & $0.157+$ & 0.073 & $0.164+$ & 0.016 \\
\hline Sufficient savings & 0.123 & -0.004 & -0.021 & -0.036 & 0.039 \\
\hline \multicolumn{6}{|l|}{ Financial competence } \\
\hline Financial literacy & 0.003 & -0.041 & 0.018 & -0.004 & $-0.239 *$ \\
\hline Numeracy & $-0.148+$ & 0.131 & $0.168 *$ & -0.089 & -0.085 \\
\hline \multicolumn{6}{|l|}{ Personality traits } \\
\hline Conscientiousness & 0.118 & -0.022 & -0.087 & $-0.237 * *$ & -0.101 \\
\hline Patience & -0.063 & 0.036 & 0.107 & $0.152+$ & 0.103 \\
\hline WTR financial & 0.052 & $-0.201 *$ & -0.019 & -0.140 & $-0.308 * *$ \\
\hline \multicolumn{6}{|l|}{ Demographics } \\
\hline Age & $0.085+$ & -0.041 & -0.040 & 0.030 & -0.020 \\
\hline Female & 0.097 & $-0.201 *$ & -0.070 & 0.067 & $-0.273^{* *}$ \\
\hline Married & 0.105 & -0.397 & -0.084 & -0.227 & 0.057 \\
\hline Tier 1 & 0.103 & 0.081 & 0.035 & 0.099 & 0.138 \\
\hline College or diploma & $0.313^{* *}$ & 0.134 & -0.017 & $-0.268 *$ & 0.085 \\
\hline University degree & $0.378^{* * *}$ & $0.244 *$ & -0.121 & $-0.269 * *$ & $0.265 *$ \\
\hline Private sector & 0.063 & -0.044 & 0.090 & -0.039 & 0.011 \\
\hline Retired & 0.076 & $0.299 *$ & 0.044 & $-0.421^{* * *}$ & 0.195 \\
\hline \multicolumn{6}{|l|}{ Health and long-term care } \\
\hline Health & $-0.281 *$ & $-0.307 * *$ & -0.064 & 0.000 & -0.114 \\
\hline Health improved & $0.167+$ & $-0.217 *$ & $0.156+$ & 0.006 & $0.188+$ \\
\hline ADL limitations & -0.011 & -0.204 & 0.113 & 0.075 & 0.260 \\
\hline IADL limitations & 0.049 & 0.212 & -0.200 & -0.039 & -0.094 \\
\hline Life expectancy & -0.078 & -0.066 & 0.015 & -0.098 & $-0.152+$ \\
\hline Spouse health & -0.062 & 0.314 * & -0.033 & 0.038 & -0.051 \\
\hline Expect informal care & 0.091 & -0.030 & $0.273 *$ & 0.059 & $-0.283+$ \\
\hline Expect nursing home & -0.141 & 0.052 & -0.092 & -0.162 & -0.032 \\
\hline Prefer informal care & -0.125 & 0.037 & -0.138 & 0.105 & $-0.261 * *$ \\
\hline Prefer nursing home & 0.008 & 0.112 & -0.093 & -0.117 & 0.111 \\
\hline \multicolumn{6}{|l|}{ Intergenerational aspects } \\
\hline 1 child & -0.204 & 0.176 & 0.109 & $-0.379+$ & $-0.442+$ \\
\hline $2+$ children & -0.024 & 0.041 & 0.260 & $-0.461+$ & $-0.538+$ \\
\hline Son & $-0.214 *$ & 0.022 & $0.140+$ & -0.005 & 0.060 \\
\hline Child same $\mathrm{HH}$ & 0.063 & $0.169 *$ & $0.138+$ & 0.030 & $0.156+$ \\
\hline Grandchildren & -0.040 & -0.098 & -0.134 & $0.165+$ & $-0.315 * *$ \\
\hline Children personal income & -0.125 & $0.185 *$ & -0.003 & 0.038 & $0.319^{* * *}$ \\
\hline Intended bequest & -0.092 & -0.042 & $0.282 * * *$ & $-0.277^{* * *}$ & 0.001 \\
\hline \multicolumn{6}{|c|}{ Instructional Manipulation Check } \\
\hline Passed IMC 1 & -0.080 & 0.039 & -0.078 & -0.086 & $-0.215+$ \\
\hline Passed IMC 2 & 0.141 & -0.023 & -0.017 & 0.051 & -0.005 \\
\hline Survey time & -0.023 & $0.264 * *$ & -0.093 & $-0.234^{* *}$ & -0.102 \\
\hline Intercept & -0.345 & -0.109 & -0.541 & -0.049 & $-0.618+$ \\
\hline Intercept & 0.468 & $0.901 *$ & 0.082 & 0.512 & -0.267 \\
\hline Intercept & $1.308^{* * *}$ & $1.723 * * *$ & $1.158^{* * *}$ & $1.398^{* * *}$ & -0.013 \\
\hline Intercept & $2.090 * * *$ & $2.469^{* * *}$ & $2.171^{* * *}$ & $3.147^{* * *}$ & 0.498 \\
\hline $\mathrm{N}$ & 977 & 977 & 977 & 977 & 977 \\
\hline
\end{tabular}


Likelihood Ratio test

Chi-Square
$\operatorname{Pr}>$ Chi-Square

80.6

131.1

0.000

96.8

0.000

143.0

176.2

0.000

Note: This table gives the results of ordered probit regressions of different uses of the reverse mortgage payments on covariates. Variables are defined in Appendix D. ${ }^{+},{ }^{*},{ }^{* *}$, and ${ }^{* * *}$ denote statistical significance at the 10\%, 5\%, 1\%, and $0.1 \%$ level, respectively.

Table 5: Explaining the use of reverse mortgage payments - Survey 2 (Ages 20-49).

\begin{tabular}{|c|c|c|c|c|c|}
\hline Dependent variable & $\begin{array}{l}\text { Live more } \\
\text { comfortably }\end{array}$ & $\begin{array}{l}\text { Better medical/ } \\
\text { aged care }\end{array}$ & $\begin{array}{l}\text { Support grand/ } \\
\text { children }\end{array}$ & $\begin{array}{l}\text { Financial } \\
\text { flexibility }\end{array}$ & Other \\
\hline \multicolumn{6}{|c|}{ Reverse mortgage knowledge and understanding } \\
\hline Product familiar & 0.175 * & -0.106 & 0.110 & 0.057 & 0.149 \\
\hline Product understanding & 0.072 & 0.012 & 0.032 & 0.101 & $0.291 * *$ \\
\hline Product quiz & -0.096 & 0.218 * & $-0.259 * *$ & $-0.205 *$ & -0.084 \\
\hline \multicolumn{6}{|l|}{ Economic factors } \\
\hline Personal income & 0.016 & -0.129 & -0.016 & 0.077 & -0.109 \\
\hline Household savings & 0.053 & 0.122 & -0.044 & 0.007 & -0.039 \\
\hline Household debt & -0.088 & $-0.154+$ & -0.032 & 0.020 & -0.089 \\
\hline No. properties & -0.042 & -0.022 & -0.053 & 0.042 & $0.125+$ \\
\hline Property value & -0.183 & 0.120 & 0.100 & 0.052 & 0.037 \\
\hline Mortgage & 0.058 & $0.175+$ & -0.066 & -0.011 & -0.062 \\
\hline Private housing loan & $0.235+$ & 0.079 & 0.001 & $-0.231+$ & 0.022 \\
\hline Stocks & 0.081 & 0.122 & -0.056 & $-0.143+$ & -0.067 \\
\hline \multicolumn{6}{|l|}{ Parents' economic factors } \\
\hline Parents household income & -0.038 & -0.042 & 0.056 & 0.016 & 0.072 \\
\hline Parents no. properties & $-0.143 *$ & $0.123+$ & -0.067 & -0.097 & -0.031 \\
\hline Parents property value & $0.217 *$ & -0.062 & -0.001 & -0.004 & -0.178 \\
\hline Parents mortgage & 0.099 & 0.063 & -0.107 & 0.111 & -0.054 \\
\hline Parents private housing loan & -0.019 & 0.190 & -0.112 & -0.095 & -0.189 \\
\hline Parents sufficient income & 0.144 & 0.118 & 0.049 & -0.072 & -0.015 \\
\hline Parents sufficient savings & -0.126 & -0.087 & 0.027 & 0.148 & -0.090 \\
\hline \multicolumn{6}{|l|}{ Financial competence } \\
\hline Financial literacy & -0.040 & $0.161+$ & $-0.244 * *$ & -0.036 & 0.003 \\
\hline Numeracy & 0.028 & -0.125 & 0.015 & -0.014 & -0.114 \\
\hline \multicolumn{6}{|l|}{ Personality traits } \\
\hline Conscientiousness & 0.115 & $-0.161+$ & -0.003 & -0.052 & $-0.233 *$ \\
\hline Patience & -0.046 & 0.018 & -0.115 & -0.104 & -0.141 \\
\hline WTR financial & -0.142 & 0.100 & 0.078 & $0.165^{*}$ & $0.306^{* *}$ \\
\hline \multicolumn{6}{|l|}{ Demographics } \\
\hline Age & 0.107 & -0.039 & 0.112 & $0.122+$ & 0.125 \\
\hline Female & 0.079 & 0.013 & $-0.153 *$ & -0.067 & -0.056 \\
\hline Married & 0.261 & -0.247 & -0.096 & 0.022 & -0.193 \\
\hline Tier 1 & -0.047 & $-0.100+$ & -0.026 & 0.031 & -0.089 \\
\hline College or diploma & 0.344 * & 0.256 & 0.032 & 0.073 & -0.097 \\
\hline University degree & 0.223 & 0.251 & -0.048 & 0.126 & $-0.413 *$ \\
\hline Private sector & -0.085 & $0.164+$ & 0.009 & $0.138+$ & -0.142 \\
\hline Retired & -1.046 & 0.076 & 5.103 & -0.120 & -4.105 \\
\hline \multicolumn{6}{|l|}{ Parents' demographics } \\
\hline Parents age & -0.008 & 0.074 & $-0.190 * *$ & -0.092 & -0.019 \\
\hline Parents college or diploma & -0.044 & $-0.161+$ & 0.054 & -0.054 & -0.094 \\
\hline Parents university & 0.101 & 0.152 & -0.104 & 0.026 & $0.299 * *$ \\
\hline Parents private sector & 0.014 & -0.003 & -0.123 & $-0.138+$ & -0.014 \\
\hline Parents retired & 0.001 & 0.049 & -0.038 & -0.142 & -0.132 \\
\hline \multicolumn{6}{|l|}{ Parents' health and long-term care } \\
\hline Parents health & -0.100 & $-0.212 *$ & 0.102 & -0.140 & $-0.252 *$ \\
\hline Parents ADL limitations & 0.035 & 0.073 & $-0.262 *$ & -0.046 & $0.308 *$ \\
\hline Parents IADL limitations & -0.007 & -0.168 & $0.262 *$ & -0.067 & $-0.388 *$ \\
\hline Expect informal care for parents & 0.062 & -0.034 & 0.017 & -0.200 & $-0.400 *$ \\
\hline Expect nursing home for parents & -0.041 & -0.202 & -0.041 & 0.164 & -0.025 \\
\hline Prefer informal care for parents & 0.092 & -0.015 & 0.110 & 0.114 & $-0.151+$ \\
\hline
\end{tabular}




\begin{tabular}{|c|c|c|c|c|c|}
\hline Prefer nursing home for parents & 0.049 & 0.223 & $-0.241+$ & $-0.219+$ & 0.202 \\
\hline \multicolumn{6}{|l|}{ Intergenerational aspects } \\
\hline 1 child & -0.249 & -0.124 & 0.180 & -0.110 & -0.061 \\
\hline $2+$ children & -0.224 & -0.281 & 0.277 & -0.241 & -0.307 \\
\hline Siblings & -0.060 & -0.067 & -0.010 & -0.046 & $0.183+$ \\
\hline Parents same HH & -0.119 & $0.176+$ & 0.009 & 0.046 & 0.056 \\
\hline Parents intended bequest & -0.065 & $-0.194 *$ & $0.168 *$ & -0.068 & 0.061 \\
\hline \multicolumn{6}{|l|}{ Instructional Manipulation Check } \\
\hline Passed IMC 1 & -0.006 & -0.051 & -0.084 & -0.023 & -0.023 \\
\hline Passed IMC 2 & 0.026 & -0.005 & -0.079 & 0.012 & -0.047 \\
\hline Survey time & 0.050 & 0.041 & -0.031 & -0.043 & -0.119 \\
\hline Intercept & -0.488 & -0.349 & 0.256 & -0.390 & 0.027 \\
\hline Intercept & 0.321 & 0.643 & $0.919 *$ & 0.232 & 0.271 \\
\hline Intercept & $1.152 * *$ & $1.434^{* *}$ & $1.722 * * *$ & $1.134 * *$ & 0.544 \\
\hline Intercept & $2.134^{* * *}$ & $2.136 * * *$ & $3.103^{* * *}$ & $2.620 * * *$ & $1.201^{* *}$ \\
\hline $\mathrm{N}$ & 925 & 925 & 925 & 925 & 925 \\
\hline \multicolumn{6}{|l|}{ Likelihood Ratio test } \\
\hline Chi-Square & 57.3 & 127.9 & 124.6 & 59.5 & 138.3 \\
\hline $\operatorname{Pr}>$ Chi-Square & 0.254 & 0.000 & 0.000 & 0.194 & 0.000 \\
\hline
\end{tabular}

Note: This table gives the results of ordered probit regressions of different uses of the reverse mortgage payments on covariates. Variables are defined in Appendix D. ${ }^{+},{ }^{*},{ }^{* *}$, and ${ }^{* * *}$ denote statistical significance at the $10 \%, 5 \%, 1 \%$, and $0.1 \%$ level, respectively.

\section{Conclusion}

In this paper, we designed, fielded and analyzed two large surveys to ascertain the potential demand for reverse mortgages in China. We developed a flexible product design that overcomes issues raised with an unsuccessful reverse mortgage product currently piloted in China and found high stated demand for this product among educated urban Chinese. The high level of interest was consistent between older homeowners and adult children (of older homeowners) who were asked whether they would recommend the product to their parents. $89 \%$ of the older homeowners were interested in the product along with $84 \%$ of the adult children who would recommend the product to their parents. As in previous studies of reverse mortgage demand we find greater interest by those with both a familiarity and objective understanding of reverse mortgages, as well as the liquidity constrained who would benefit most from access to such a product.

Our results have several implications for the design and marketing of reverse mortgages. First, reverse mortgages are complex financial products. To increase demand, providers need to describe these products in an easy-to-understand way and should address key consumer concerns directly. We developed a detailed product description that was very well understood by the survey participants. The product de- 
scription addressed concerns about reverse mortgages identified in the academic literature, in the media and in focus group tests, and included a numerical example to help understanding. This product description likely facilitated the strong stated demand for the hypothetical reverse mortgage product $\mathrm{ABC}$. We also found that previous knowledge of reverse mortgages was strongly associated with demand which suggests that advertisements and media reports can increase demand. Overall our results are consistent with the findings reported by Davidoff et al. (2017) on the importance of product knowledge and understanding for reverse mortgage demand.

Second, our results suggest that reverse mortgages should be marketed to both older residents and their adult children. In particular, reverse mortgage providers should encourage the broader family unit to discuss the use of housing wealth in retirement. Doing so can reduce the potential expectation mismatches as evident in our data, where some older homeowners rejected the reverse mortgage because they wanted to leave their property to children or grandchildren, while very few of the adult children were concerned about this. At the same time, a number of the adult children thought their parents would not be interested, while approval rates were high in the older sample.

Third, narrow framing of the reverse mortgage as a tool to finance specific expenditures in retirement did not increase reverse mortgage demand. Instead, the survey participants wanted to use the product payments for a range of purposes, including to fund a more comfortable retirement, to pay for better medical or aged care services, to support children or grandchildren, or simply to have more financial flexibility in retirement. Individual characteristics impacted how the older homeowner participants wanted to use the reverse mortgage payments. Participants with poorer health wanted to fund better medical services, while participants with stronger bequest motives or those expecting informal care wanted to support children or grandchildren with the reverse mortgage payments.

\section{References}

Agnew, J. R., Anderson, L. R., Gerlach, J. R., and Szykman, L. R. (2008). Who chooses annuities? An experimental investigation of the role of gender, framing, and defaults. American Economic Review, 98(2), 418-22. 
Agnew, J. R., Bateman, H., Eckert, C., Iskhakov, F., Louviere, J., and Thorp, S. (2016). First impressions matter: An experimental investigation of online financial advice. Management Science, 64(1), $288-307$.

Andreu, E. S., Alessie, R., and Angelini, V. (2018). The retirement-savings puzzle reviewed: The role of housing and bequests. Journal of Economic Surveys. Forthcoming.

Asia Insurance Review (2017). China: Reverse mortgage scheme struggles to take off. Asia Insurance Review. 31 August 2017.

Bateman, H., Louviere, J., and Thorp, S. (2014). Understanding how consumers make financial choices. In T. Harrison and H. Estelami, editors, The Routledge Companion to Financial Services Marketing, pages 62-77. Routledge.

Cocco, J. F. and Lopes, P. (2014). Reverse mortgage design. Technical report, London Business School.

Davidoff, T. (2009). Housing, health, and annuities. Journal of Risk and Insurance, 76(1), 31-52.

Davidoff, T., Gerhard, P., and Post, T. (2017). Reverse mortgages: What homeowners (don't) know and how it matters. Journal of Economic Behavior E Organization, 133, 151-171.

Dillingh, R., Prast, H., Rossi, M., and Brancati, C. U. (2017). Who wants to have their home and eat it too? Interest in reverse mortgages in the Netherlands. Journal of Housing Economics, 38, 25-37.

Fang, H. and Feng, J. (2018). The Chinese Pension System. NBER Working Paper No. 25088.

Fang, H., Gu, Q., Xiong, W., and Zhou, L.-A. (2016). Demystifying the Chinese housing boom. NBER Macroeconomics Annual, 30(1), 105-166.

Fornero, E., Rossi, M., and Brancati, M. C. U. (2016). Explaining why, right or wrong, (Italian) households do not like reverse mortgages. Journal of Pension Economics and Finance, 15(02), 180-202.

Gan, L., Yin, Z., Jia, N., Xu, S., Ma, S., and Zheng, L. (2014). Data you need to know about China: Research Report of China Household Finance Survey (2012). Springer Verlag.

Hanewald, K., Post, T., and Sherris, M. (2016). Portfolio choice in retirement-What is the optimal home equity release product? Journal of Risk and Insurance, 83(2), 421-446.

Jefferson, T., Austen, S., Ong, R., Haffner, M. E., and Wood, G. A. (2017). Housing equity withdrawal: Perceptions of obstacles among older Australian home owners and associated service providers. Journal of Social Policy, 46(3), 623-642.

Lipkus, I. M., Samsa, G., and Rimer, B. K. (2001). General performance on a numeracy scale among highly educated samples. Medical Decision Making, 21(1), 37-44.

Lusardi, A. and Mitchell, O. S. (2011a). Financial literacy and planning: Implications for retirement wellbeing. In A. Lusardi and O. S. Mitchell, editors, Financial literacy: Implications for retirement security and the financial marketplace, pages 17-39. Oxford University Press. 
Lusardi, A. and Mitchell, O. S. (2011b). Financial literacy around the world: An overview. Journal of Pension Economics \& Finance, 10(4), 497-508.

Merton, R. and Lai, R. N. (2016). On an Efficient Design of Reverse Mortgages: A Possible Solution for Aging Asian Populations. Available at SSRN: https://ssrn.com/abstract=3075087.

Merton, R. C. (2008). The future of retirement planning. In Z. Bodie, D. McLeavey, and L. B. Siegel, editors, The Future of Life-Cycle Saving and Investing, Second Edition. CFA Institute.

Mitchell, O. S. and Piggott, J. (2004). Unlocking housing equity in Japan. Journal of the Japanese and International Economies, 18(4), 466-505.

Moulton, S., Loibl, C., and Haurin, D. (2017). Reverse mortgage motivations and outcomes: Insights from survey data. Cityscape, 19(1), 73-98.

Nakajima, M. and Telyukova, I. A. (2017). Reverse mortgage loans: A quantitative analysis. The Journal of Finance, 72(2), 911-950.

Oppenheimer, D. M., Meyvis, T., and Davidenko, N. (2009). Instructional manipulation checks: Detecting satisficing to increase statistical power. Journal of Experimental Social Psychology, 45(4), 867-872.

Park, A. and Shen, Y. (2015). Understanding wealth and housing inequality among China's older population. China Economic Journal, 8(3), 288-307.

Phang, S.-Y. (2018). Home equity extraction for retiring financing. In S.-Y. Phang, editor, Policy Innovations for Affordable Housing In Singapore. UK: Palgrave Macmillan.

Rosenzweig, M. and Zhang, J. (2014). Co-residence, life-cycle savings and inter-generational support in urban China. NBER Working Paper No. 20057.

United Nations (2017). World Population Prospects: The 2017 Revision. United Nations, Department of Economic and Social Affairs, Population Division, New York. Custom data acquired via website.

Van Rooij, M., Lusardi, A., and Alessie, R. (2011). Financial literacy and stock market participation. Journal of Financial Economics, 101(2), 449-472.

World Bank (2016). Live Long and Prosper: Aging in East Asia and Pacific. World Bank, Washington, DC.

Wu, S., Bateman, H., Stevens, R., and Thorp, S. (2018). Reducing the under-insurance puzzle by product design: Experimental evidence of life care annuity demand. ARC Centre of Excellence in Population Ageing Research (CEPAR) Working Paper 2018/2.

Xie, Y. and Jin, Y. (2015). Household wealth in China. Chinese Sociological Review, 47(3), 203-229.

Zhong, X. and Li, B. (2017). New intergenerational contracts in the making?-the experience of urban china. Journal of Asian Public Policy, 10(2), 167-182. 